\title{
Assessment of Triazine Herbicides Residual in Fruit and Vegetables Using Ultrasound Assisted Extraction-Dispersive Liquid-Liquid Microextraction with Solidification of Floating Organic Drop
}

\author{
Yahya Pasdar, ${ }^{a}$ Meghdad Pirsaheb, ${ }^{a}$ Reza Akramipour, ${ }^{b}$ Toraj Ahmadi-Jouibari, ${ }^{c}$ \\ Nazir Fattahi, *,a Kiomars Sharafi, ${ }^{a, d}$ and Hamid Reza Ghaffari ${ }^{e}$ \\ ${ }^{a}$ Research Center for Environmental Determinants of Health (RCEDH), ${ }^{b}$ School of Medical and \\ ${ }^{c}$ Clinical Research Development Center, Imam Khomeini Hospital, \\ Kermanshah University of Medical Sciences, Kermanshah, Iran \\ ${ }^{d}$ Department of Environmental Health Engineering, School of Public Health, \\ Tehran University of Medical Sciences, Tehran, Iran \\ ${ }^{e}$ Social Determinants in Health Promotion Research Center, \\ Hormozgan University of Medical Sciences, Bandar Abbas, Iran
}

\begin{abstract}
A simple, inexpensive, reliable and environmentally friendly method based on ultrasound assisted extraction (UAE) combined with dispersive liquid-liquid microextraction with solidification of floating organic drop (DLLME-SFO) was developed for the simultaneous determination of four triazines in fruit and vegetable samples. Parameters affecting the extraction process were studied and optimized. Under the optimum conditions (sonication time: $15 \mathrm{~min}$; extraction solvent: $30.0 \mu \mathrm{L}$ 1-undecanol; disperser solvent: $1.0 \mathrm{~mL}$ acetonitrile; $\mathrm{pH}$ : 7; and extraction time: $0 \mathrm{~min}$ ), extraction recoveries for different fruit and vegetables are in the range of $65-86 \%$. The calibration graphs are linear in the range of $5-800 \mu \mathrm{g} \mathrm{kg}^{-1}$, with the correlation coefficient $\left(\mathrm{r}^{2}\right)$ higher than 0.9985 . The limits of detection (LODs) are in the range of $1-2 \mu \mathrm{g} \mathrm{kg}^{-1}$, which are lower than the maximum residue levels (MRLs) established by various official organizations. Repeatability (intra-day) and reproducibility (inter-day) of the method based on five replicate measurements of $100 \mu \mathrm{g} \mathrm{kg}^{-1}$ of herbicides were in the range of 3.6-5.4\% and 4.5-6.3\%, respectively.
\end{abstract}

Keywords: ultrasound assisted extraction, dispersive liquid-liquid microextraction, triazine herbicides, fruit, vegetables

\section{Introduction}

Triazine herbicides are a class of pre- and post-emergent broadleaf herbicides with similar chemical structure that inhibit the growth of weeds through disruption of photosynthesis pathways. ${ }^{1}$ The intensive application of triazines has resulted in the contamination of the atmosphere, ground and waste waters, agricultural products and, consequently, in the direct and indirect pollution of food and food products. ${ }^{2}$ Studies have concluded that triazine herbicides represent potentials for toxic effects on human health, including birth defects, cancers and interruption of hormone functions. ${ }^{3}$ The herbicide residues

*e-mail: nazirfatahi@yahoo.com in agricultural products and foods become a serious concern. Therefore, a sensitive and accurate method for determination of triazine herbicides in fruit, vegetables and foods is particularly important to guarantee public health and safety. ${ }^{4,5}$

Many countries and regions have established the criteria of maximum residue limits (MRLs) of triazine herbicides. The Environmental Protection Agency (EPA) has provided that the MRLs of triazine herbicides in most products are $0.25 \mathrm{mg} \mathrm{kg}^{-1}$, while the European Union (EU) dictated that the MRL of terbuthylazine in vegetables is $0.05 \mathrm{mg} \mathrm{kg}^{-1}$.

Extraction and cleanup are the most challenging parts for determination of herbicides in food stuffs, especially in fruit and vegetables with inherent complex matrices. ${ }^{7}$ Additionally, the low concentrations of herbicides in 
fruit and vegetables also make the direct determining of them difficult by chromatographic methods, such as liquid chromatography (LC) or gas chromatography (GC). ${ }^{8}$ Therefore, there is a need to employ exhaustive sample preparation technique for the extraction and preconcentration of the herbicides from fruit and vegetables before determination.

Various modern sample pretreatment methods, such as liquid-liquid extraction (LLE), ${ }^{9}$ solid phase extraction (SPE),${ }^{10}$ solid phase microextraction (SPME),${ }^{11}$ supercritical fluid extraction (SFE) ${ }^{12}$ and continuous flow liquid membrane extraction (CFLME), ${ }^{13}$ have been exploited for extracting pesticide residues from various farm products. These techniques are time-consuming, expensive and especially relating to LLE, hazardous to health due to the high volume of potentially toxic solvents used. ${ }^{14}$ SPME suffers from some drawbacks: its fiber is fragile and has limited lifetime and desorption temperature, and also sample carry-over is a problem. ${ }^{15}$ Equipment of SFE are commonly huge, complex and expensive, which limits its application. Process of CFLME is not easy to control, which makes its application difficult. ${ }^{16}$

Liquid phase microextraction (LPME) method has been developed and many reports have been carried out in order to extract and determine triazine herbicides such as single drop microextraction (SDME),${ }^{17}$ hollow fiber-protected microextraction (HF-LPME), ${ }^{18}$ solid phase extraction (SPE), ${ }^{16}$ stir bar sorptive extraction (SBSE),${ }^{19}$ matrix solid phase dispersion (MSPD) ${ }^{20}$ and vortex assisted liquidliquid microextraction (VALLME) ${ }^{21}$ However, there are some drawbacks in these methods, e.g. fast stirring speed lead to break up of the organic drop in SDME, air bubble could be formed on the surface of hollow fiber and poor reproducibility due to manual cutting of the membrane in the laboratory in HF-LPME, time-consuming and expensive in SPE and SBSE, sample carry-over in MSPD and extraction is time-consuming and equilibrium could not be attained in VALLME.

In 2006, Assadi and co-workers ${ }^{22}$ developed a novel liquid phase microextraction technique, named dispersive liquid-liquid microextraction (DLLME). In recent years, DLLME is becoming particularly popular. ${ }^{23-28}$ Simplicity, rapidity, low sample volume, low cost, high recovery, high enrichment factor, and ease of method development that made it available to virtually all analytical laboratories are some advantages of the DLLME technique. However, in conventional DLLME, the density of extraction solvent should be higher than water; the applications of DLLME in most cases were limited for aqueous samples and the volume of the sedimented phase in some cases was dependent on the surrounding temperature. The high- density extraction solvents, being mostly halogenated, are generally hazardous to laboratory personnel and the environment. On the other hand, less toxic solvents, such as alcohols, alkanes, etc., have a density less than those of aqueous solutions, and are collected on the upper surface of the sample solution as a microdrop after centrifuging. One of these methods that is called solidified floating organic drop (SFO), a small volume of an organic solvent with a melting point near room temperature $\left(10-30^{\circ} \mathrm{C}\right)$ is floated on the surface of an aqueous solution. The aqueous phase is stirred for a prescribed period of time, and then the sample is transferred to an ice bath. When the organic solvent is solidified, it is transferred to a small conical vial, and the melted organic solvent is used for analyte determination. The performance of DLLME-SFO was illustrated by extraction of different organic and inorganic compounds ${ }^{29-36}$ from different matrices and several reviews have been written on this issue. ${ }^{37-39}$

Ultrasound assisted extraction (UAE) is considered a good alternative for organic compound extraction from semisolid and solid matrices which provides a more efficient contact between the solid and solvent due to an increase of both pressure (which favors penetration and transport) and temperature (improves solubility and diffusivity). UAE is a very common extraction technique for the recovery of active components, mainly due to the mild extraction conditions applied. Cavitation is the ultrasound mechanical effect that enables greater penetration of solvent into the solid sample. ${ }^{40,41}$

The aim of this work was to develop a simple, low cost and reliable analytical method for simultaneous determination of four triazine herbicides in fruit, vegetables and food samples using UAE-DLLME-SFO as a preconcentration technique followed by high performance liquid chromatography with ultraviolet detection (HPLC-UV). The UAE-DLLME-SFO technique combines advantages of both DLLME and SFO techniques; it is rapid due to the high surface area between phases and it is environmentally friendly due to the solvents used. In this work, influence of different parameters in extraction was investigated and optimized. After optimization, procedure was validated and it was finally applied to the determination of the triazine herbicides in fruit, vegetables and food stuffs.

\section{Experimental}

\section{Reagents and standards}

Standards of atrazine, cyanazine, simazine and propazine were purchased from Sigma-Aldrich (Milwaukee, WI, USA). Methanol (for spectroscopy), acetone (SupraSolv for 
gas chromatography), acetonitrile (hyper grade for liquid chromatography), 1-undecanol, 1-decanol, 1-dodecanol, hexadecane, hydrochloric acid and sodium chloride were obtained from Merck (Darmstadt, Germany). Ultra-pure water was purified on a Milli-Q water purification system (Millipore, Bedford, MA, USA). A stock standard solution containing $1 \mathrm{mg} \mathrm{mL}^{-1}$ of herbicides was prepared in HPLC grade acetonitrile. The stock solution was stored at $-20^{\circ} \mathrm{C}$. Working standard solutions were prepared daily by diluting the stock standard solution with ultra-pure water to the required concentrations.

Fresh fruit and vegetable samples (tomato, potato, cucumber, melon, watermelon, apple, pear, orange, green vegetables and stewed vegetables) were purchased from local grocery (Kermanshah, Iran).

\section{Instrumentation}

Chromatographic analysis was performed using a Knauer HPLC consisting of binary pumps Smartline-1000-1 and Smartline-1000-2 and detector Smartline-UV-2500 variable wavelength programmable (Berlin, Germany), an online solvent vacuum degasser and manual sample injector fitted with a $20 \mu \mathrm{L}$ injection loop (model 7725i, Rheodyne, Cotati, CA, USA). Chromatographic data were recorded and analyzed using Chromgate software (version 3.1). Separations were carried out on a H5-ODS $\mathrm{C}_{18}$ column $(15 \mathrm{~cm} \times 4.6 \mathrm{~mm}$, with $5 \mu \mathrm{m}$ particle size $)$ from Anachem (Luton, UK). The mobile phase was a mixture of acetonitrile-water $(72: 28, \mathrm{v} / \mathrm{v})$ and the flow-rate was $0.80 \mathrm{~mL} \mathrm{~min}^{-1}$ in isocratic elution mode and the detection was performed at the wavelength of $220 \mathrm{~nm}$. The Hettich Zentrifugen (EBA20, Tuttlingen, Germany) was used for centrifuging.

\section{Sample preparation and UAE procedure}

Fresh fruit and vegetable samples were obtained from local grocery (province of Kermanshah, Iran) which was treated with the target pesticides. In the first step, a representative portion of each sample (tomato, potato, cucumber, melon, watermelon, apple, pear, orange, green vegetables and stewed vegetables) were chopped using a kitchen knife and homogenized by Buchi Mixer B 400 (Flawil, Switzerland). Analytical portions of $1.00 \mathrm{~g}$ homogenized sample spiked or not with herbicides was exactly weighted into a $10-\mathrm{mL}$ screw cap centrifuge tube and $5.0 \mathrm{~mL}$ of acetonitrile (as extractant) were added and extracted in an ultrasonic bath (Erosonic 4D, Vicenza, Italy) for $15 \mathrm{~min}$ at room temperature. After this step $150.0 \mu \mathrm{L}$ of 1-undecanol, which is a microextraction solvent in
DLLME-SFO, was added to centrifuge tube and then it was gently shaken for 5 seconds. It followed by centrifugation at $4000 \mathrm{rpm}$ for $3 \mathrm{~min}$. The supernatant was transferred to another clean tube for further DLLME-SFO procedure.

\section{DLLME-SFO procedure}

DLLME-SFO was performed by rapid injection of $1.00 \mathrm{~mL}$ of acetonitrile extract containing triazine herbicides and 1-undecanol (approximately $30.0 \mu \mathrm{L}$ ) into a $5.00 \mathrm{~mL}$ ultra pure water which was placed in a $10-\mathrm{mL}$ glass test tube using a 1.00-mL syringe (gastight, Hamilton, Nevada, USA). A cloudy solution resulting from dispersion of fine droplets of 1-undecanol in aqueous solution was formed in the test tube. In this step, the triazine herbicides in acetonitrile were extracted into the fine droplets of 1-undecanol within few seconds. After extracting for a few seconds, the phase separation was performed by centrifugation at $5000 \mathrm{rpm}$ for 5 minutes. Accordingly, the dispersed fine droplets of the extraction phase were collected on the top of the conical test tube $(25 \pm 2 \mu \mathrm{L})$. The test tube was transferred into a beaker containing ice pieces, and the organic solvent was solidified after $5 \mathrm{~min}$. Then, the solidified solvent was transferred into a vial by laboratory spatula, where it melted immediately. Finally, the extraction solvent was injected into an HPLC for analysis.

\section{Calculations of extraction recovery and relative recovery}

The extraction recovery (ER) was defined as the percentage of the total analyte amount $\left(\mathrm{n}_{0}\right)$ which was extracted to the floated phase $\left(\mathrm{n}_{f}\right)$.

$E R \%=\frac{n_{f}}{n_{0}} \times 100=\frac{C_{f} V_{f}}{C_{0} V_{s}} \times 100$

where $\mathrm{C}_{f}$ and $\mathrm{C}_{0}$ are the concentration of analyte in the floating phase and initial concentration of the analyte in the sample; $\mathrm{V}_{f}$ and $\mathrm{V}_{s}$ are the volumes of the floating phase and sample, respectively.

The relative recovery (RR) was obtained as the following equation:

$R R \%=\frac{C_{\text {found }}-C_{\text {real }}}{C_{\text {added }}} \times 100$

where $\mathrm{C}_{\text {found }}, \mathrm{C}_{\text {real }}$, and $\mathrm{C}_{\text {added }}$ are the total concentration of analyte after addition of known amount of standard in real sample, the original concentration of analyte in real sample and the concentration of known amount of standard which was spiked to the real sample, respectively. 


\section{Results and Discussion}

In the present work, UAE-DLLME-SFO combined with HPLC-UV was developed for the determination of triazine herbicides in tomato, potato, cucumber, melon, watermelon, apple, pear, orange, green vegetables and stewed vegetables. The UAE and DLLME-SFO conditions were optimized using one variable at a time optimization method.

\section{Optimization of UAE parameters}

\section{Optimization of sonication time}

For the effect of sonication time on the extraction efficiency, additional experiments were performed using different sonication times with power of $200 \mathrm{~W}$ and $24 \mathrm{~Hz}$ at room temperature. When the sonication time increased from 5 to $15 \mathrm{~min}$, the recoveries of all analytes were increased due to the mass transfer of herbicides from cellular material to acetonitrile by diffusion and osmosis. However, the extraction efficiency had no noticeable enhancement during the sonication time increasing from 15 to $30 \mathrm{~min}$. Thus, 15 min was selected as the optimum sonication time.

\section{Selection of extractant solvent}

When combining UAE with DLLME-SFO, the extracting solvent in UAE stage must also play the role of the disperser solvent at the DLLME-SFO stage. Thereby, methanol, acetonitrile and acetone, displaying this ability, were selected for this purpose and the effect of these solvents on the extracting of analytes from matrices were investigated. The results illustrated in Figure 1 reveal that the extraction recoveries, using acetone, acetonitrile and methanol as extracting solvents, were $61-83 \%, 65-86 \%$ and $58-77 \%$, respectively, showing that acetonitrile is bit

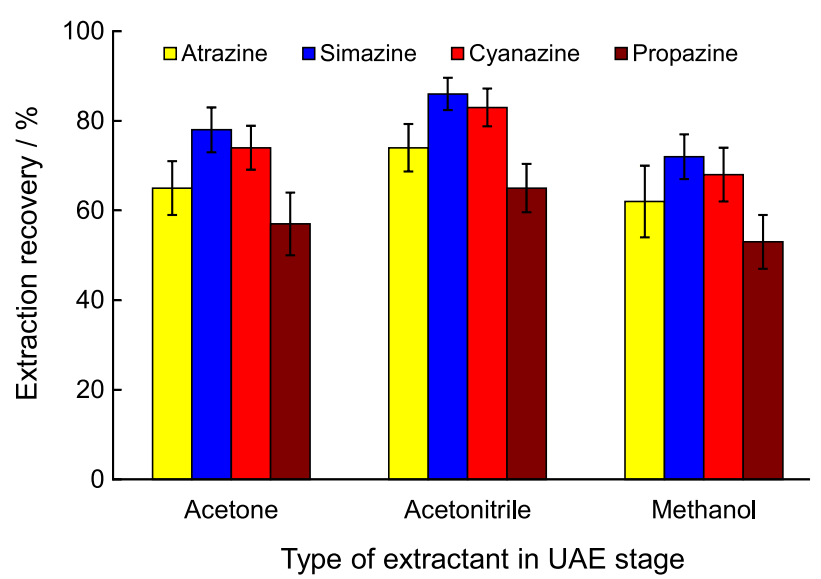

Figure 1. Effect of type of extraction solvent in UAE stage on the recovery of triazine herbicides. Conditions: sonication time, $15 \mathrm{~min}$; volume of extraction solvent in SE step, $5 \mathrm{~mL}$; water sample volume, $5.00 \mathrm{~mL}$; extraction solvent in DLLME stage and its volume, 1-undecanol, $30 \mu \mathrm{L}$; volume of disperser solvent (acetononitrile), $1.00 \mathrm{~mL}$; room temperature. better than acetone and methanol. Also, acetonitrile shows lower relative standard deviation (RSD) than acetone and methanol. Therefore acetonitrile was selected as the extraction solvent in UAE stage.

\section{Optimization of DLLME-SFO parameters}

Type of the extraction solvent and its volume

Several extracting solvents, including 1-undecanol, 1-decanol, 1-dodecanol and hexadecane were investigated. Average recoveries (triplicate) and standard deviations (SD) for different extraction solvents are shown in Figure 2. The results revealed that 1 -undecanol has the highest recoveries in comparison with the other tested solvents. Therefore, 1-undecanol was chosen for further experiments.

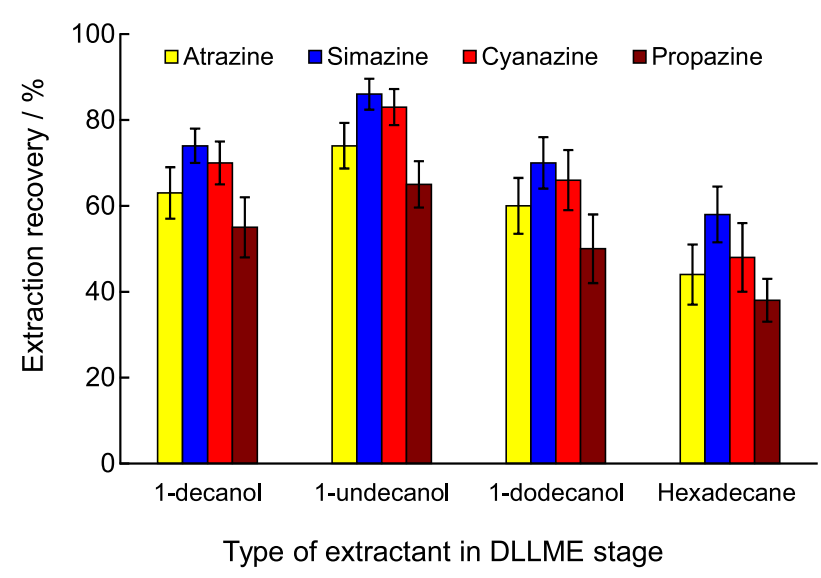

Figure 2. Effect of type of extraction solvent in DLLME-SFO stage on the recovery of triazine herbicides. Conditions: as in Figure 1 except for type of extraction solvent in UAE step, acetonitrile.

In order to select the optimum volume of extraction solvent, several experiments were performed using $1.00 \mathrm{~mL}$ of acetonitrile and different volumes of 1-undecanol (30, $40,50,60$ and $70 \mu \mathrm{L}$ ). Increasing the volume of 1 -undecanol from 30 to $70 \mu \mathrm{L}$, the volume of the floated phase increased approximately from 25 to $63 \mu \mathrm{L}$. The result shows enrichment factor decreases with increasing the volume of 1-undecanol; it is clear that by increasing the volume of 1-undecanol the volume of the floated phase increases. Therefore, the extraction recovery of the targets decreases with an increase in the volume of 1-undecanol, which might be caused by the slightly decreased concentration of the analytes in the floating phase as a result of the dilution effect. A volume less than $20 \mu \mathrm{L}$ of 1 -undecanol resulted in a floated volume less than $20 \mu \mathrm{L}$ which was insufficient for determination by the HPLC. Thus, in order to have a high enhancement factor and good repeatability, $30 \mu \mathrm{L}$ of 1-undecanol was selected as the optimum volume of the extracting solvent. 
Type of the disperser solvent and its volume

According to the results in Selection of extractant solvent section, acetonitrile was selected as disperser solvent. To investigate the effect of acetonitrile volume on the extraction efficiency, several volumes of acetonitrile in the range of $0.25-2.00 \mathrm{~mL}$ containing different volumes of 1-undecanol were studied. Increasing the volume of 1-undecanol by increasing the volume of acetonitrile is necessary to obtain the constant volume of the floated phase $(25 \pm 2 \mu \mathrm{L})$ in all experiments. According to the results in Figure 3, the extraction efficiency increased by increasing the volume of acetonitrile up to $1.00 \mathrm{~mL}$ and decreased thereafter. At a low volume of acetonitrile, the cloudy state could not be formed completely; therefore, the extraction efficiency was low. On the other hand, increasing of the disperser solvent volume led to decreased extraction efficiency due to the enhanced solubility of analytes in the aqueous solution. As a result, $1.00 \mathrm{~mL}$ was used as the optimal volume of acetonitrile for further studies.

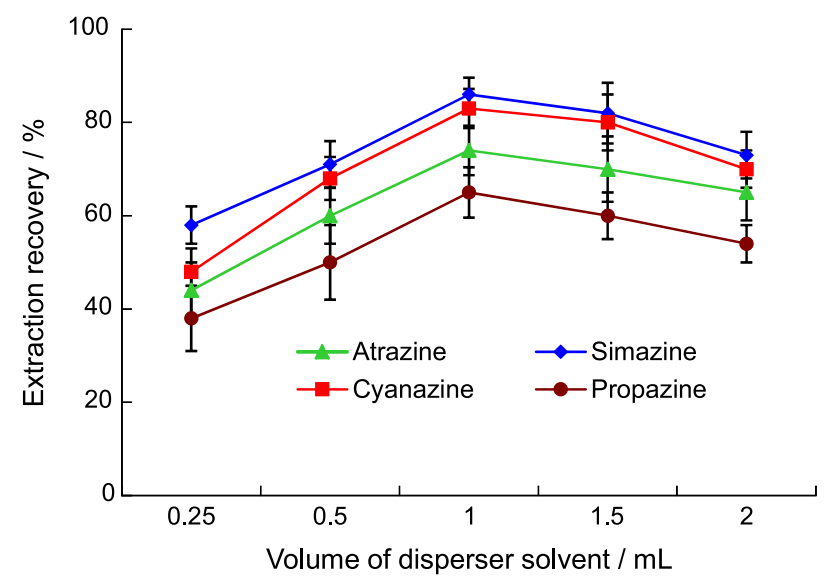

Figure 3. Effect of volume of disperser solvent in DLLME-SFO step on the recovery of triazine herbicides. Conditions: as in Figure 1 except for type of extraction solvent in UAE step, acetonitrile.

\section{Effect of $\mathrm{pH}$}

Triazine herbicides can be hydrolyzed in strong acid or alkali environment. In DLLME-SFO stage, for investigating the effect of aqueous solution $\mathrm{pH}$ on the extraction efficiency, various experiments were performed by different $\mathrm{pH}$ of aqueous solution (from 3 to 10 ) with hydrochloric acid, sodium acetate and sodium hydroxide. Other experimental conditions were kept constant. It can be seen from Figure 4 that the recoveries of triazines were nearly constant in the $\mathrm{pH}$ range of 6-9. Therefore, the use of an acidic or buffer solution for the $\mathrm{pH}$ adjustment, being the contamination sources, was not necessary.

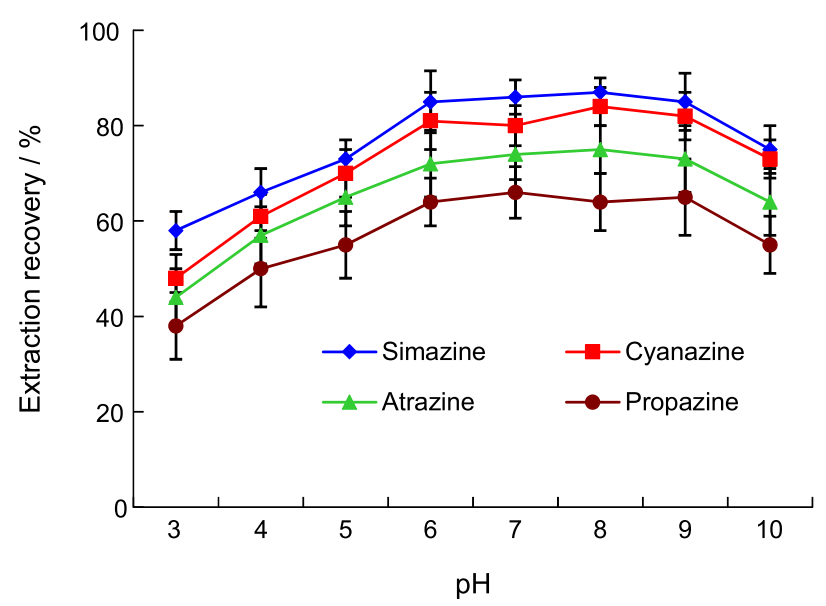

Figure 4. Effect of pH in DLLME-SFO step on the recovery of triazine herbicides. Conditions: as in Figure 1 except for type of extraction solvent in UAE step, acetonitrile.

\section{Analytical performance}

Important parameters such as the linear range (LR), correlation coefficients $\left(\mathrm{r}^{2}\right)$, precision, limit of detection (LOD) and limit of quantification (LOQ) were determined to evaluate the performance of the method. Table 1 summarizes the analytical characteristics of the optimized method. The calculated calibration curves gave a high level of linearity in the range of $5-800 \mu \mathrm{g} \mathrm{kg}^{-1}$. Correlation coefficients $\left(\mathrm{r}^{2}\right)$ ranged from 0.9985 to 0.9995 . The LODs, based on a signal-to-noise ratio of 3:1 ( $\mathrm{S} / \mathrm{N}=3)$, ranged from 1 to $2 \mu \mathrm{g} \mathrm{kg}^{-1}$ which is much lower than the maximum residues levels (MRLs) established by European Union regulation. The LOQs, based on a signal-to-noise ratio of 10:1 ( $\mathrm{S} / \mathrm{N}=10)$ were in the range of $3-6 \mu \mathrm{g} \mathrm{kg}^{-1}$. The repeatability (intra-day) and reproducibility (inter-day)

Table 1. Analytical characteristics of the optimized method

\begin{tabular}{|c|c|c|c|c|c|c|c|}
\hline Analyte & $\mathrm{ER}^{\mathrm{a}} / \%$ & $\begin{array}{c}\mathrm{RSD}^{\mathrm{b}} / \% \\
(\mathrm{n}=5, \text { intra-day })\end{array}$ & $\begin{array}{c}\mathrm{RSD} / \% \\
(\mathrm{n}=5, \text { inter-day })\end{array}$ & $\begin{array}{c}\mathrm{LR}^{\mathrm{c}} / \\
\left(\mu \mathrm{g} \mathrm{kg}^{-1}\right)\end{array}$ & $\mathrm{r}^{2 \mathrm{~d}}$ & $\begin{array}{c}\mathrm{LOD}^{\mathrm{e}} / \\
\left(\mu \mathrm{g} \mathrm{kg}^{-1}\right)\end{array}$ & $\begin{array}{c}\mathrm{LOQ}^{\mathrm{f}} / \\
\left(\mu \mathrm{g} \mathrm{kg}^{-1}\right)\end{array}$ \\
\hline Atrazine & 74 & 5.3 & 5.2 & $8-800$ & 0.9988 & 2 & 6 \\
\hline Simazine & 86 & 3.6 & 4.5 & $5-500$ & 0.9995 & 1 & 3 \\
\hline Cyanazine & 83 & 4.2 & 4.9 & $5-500$ & 0.9991 & 1 & 3 \\
\hline Propazine & 65 & 5.4 & 6.3 & $8-800$ & 0.9985 & 2 & 6 \\
\hline
\end{tabular}

${ }^{\mathrm{a}}$ Extraction recovery; ${ }^{\mathrm{b}}$ relative standard deviation at concentration of $100 \mu \mathrm{g} \mathrm{kg}^{-1}$ of pesticides; ${ }^{\mathrm{c} l i n e a r}$ range; ${ }^{\mathrm{d}} \mathrm{square}$ of correlation coefficient; ${ }^{\mathrm{e}}$ limit of detection for $\mathrm{S} / \mathrm{N}=3$; fimit of quantification for $\mathrm{S} / \mathrm{N}=10$. 
were studied by extracting the spiked fruit and vegetables samples (100 $\mu \mathrm{g} \mathrm{kg}^{-1}$ for each analyte). The intra-day RSDs were determined by five analyses of spiked samples within one day, whereas the inter-day precision was examined by analyzing the spiked samples for five consecutive days. The repeatability and reproducibility were calculated to be in the range of 3.6-5.4\% and 4.5-6.3\%, respectively.

\section{Analysis of real fruit and vegetables}

In order to demonstrate the applicability of the proposed method, it was used for the determination of triazines in ten fruit and vegetables, including tomato, potato, cucumber, melon, watermelon, apple, pear, orange, green vegetable and stewed vegetable samples which was treated with the target herbicides. For potato, simazine and cyanazine were detected at the concentration level of $34.5 \pm 2.6$ and $22.3 \pm 2.2 \mu \mathrm{g} \mathrm{kg}^{-1}$, respectively. For tomato, atrazine was detected at the concentration level of $14.2 \pm 3.5 \mu \mathrm{g} \mathrm{kg}^{-1}$. The results for cucumber, melon, watermelon, apple, pear, orange, green vegetable and stewed vegetable samples indicated that they were free of triazine herbicides contamination. Then these samples were spiked with four triazines at two concentration levels of 50 and $100 \mu \mathrm{g} \mathrm{kg}^{-1}$, and analyzed by the present method under the optimal conditions. Table 2 shows that the recoveries of all analytes range from 91 to $108 \%$. Figure 5

Table 2. Concentrations of triazines in fruit and vegetables with and without spiking of target analytes

\begin{tabular}{|c|c|c|c|c|c|}
\hline Sample & Analyte & $\begin{array}{c}\text { Concentration } \\
(\text { mean } \pm \mathrm{SD})^{\mathrm{a}} /\left(\mu \mathrm{g} \mathrm{kg}^{-1}\right)\end{array}$ & $\begin{array}{l}\text { Added / } \\
\left(\mu \mathrm{gg}^{-1}\right) \\
\end{array}$ & $\begin{array}{c}\text { Found } \\
(\text { mean } \pm \mathrm{SD}) /\left(\mu \mathrm{g} \mathrm{kg}^{-1}\right)\end{array}$ & $\begin{array}{c}\text { Relative } \\
\text { recovery / \% }\end{array}$ \\
\hline \multirow{4}{*}{ Tomato } & atrazine & $14.2 \pm 3.5$ & 100 & $115.7 \pm 7.4$ & 101 \\
\hline & simazine & n.d. & 100 & $96.3 \pm 5.2$ & 96 \\
\hline & cyanazine & n.d. & 100 & $102.0 \pm 6.8$ & 102 \\
\hline & propazine & n.d. & 100 & $93.1 \pm 3.4$ & 93 \\
\hline \multirow{4}{*}{ Potato } & atrazine & n.d. & 50 & $53.2 \pm 2.6$ & 106 \\
\hline & simazine & $34.5 \pm 2.6$ & 50 & $86.2 \pm 5.7$ & 103 \\
\hline & cyanazine & $22.3 \pm 2.2$ & 50 & $70.4 \pm 4.3$ & 96 \\
\hline & propazine & n.d. & 50 & $46.6 \pm 2.2$ & 93 \\
\hline \multirow{4}{*}{ Cucumber } & atrazine & n.d. & 100 & $103.0 \pm 4.5$ & 103 \\
\hline & simazine & n.d. & 100 & $91.4 \pm 5.3$ & 91 \\
\hline & cyanazine & n.d. & 100 & $99.3 \pm 6.4$ & 99 \\
\hline & propazine & n.d. & 100 & $107.4 \pm 8.2$ & 107 \\
\hline \multirow{4}{*}{ Melon } & atrazine & n.d. & 50 & $50.5 \pm 3.4$ & 101 \\
\hline & simazine & n.d. & 50 & $48.3 \pm 2.2$ & 97 \\
\hline & cyanazine & n.d. & 50 & $53.0 \pm 6.7$ & 106 \\
\hline & propazine & n.d. & 50 & $46.8 \pm 5.1$ & 94 \\
\hline \multirow{4}{*}{ Watermelon } & atrazine & n.d. & 100 & $93.0 \pm 3.8$ & 93 \\
\hline & simazine & n.d. & 100 & $91.7 \pm 6.2$ & 92 \\
\hline & cyanazine & n.d. & 100 & $97.5 \pm 5.9$ & 98 \\
\hline & propazine & n.d. & 100 & $100.5 \pm 3.3$ & 101 \\
\hline \multirow{4}{*}{ Apple } & atrazine & n.d. & 50 & $51.4 \pm 2.8$ & 103 \\
\hline & simazine & n.d. & 50 & $49.8 \pm 4.6$ & 100 \\
\hline & cyanazine & n.d. & 50 & $50.6 \pm 3.4$ & 101 \\
\hline & propazine & n.d. & 50 & $52.5 \pm 5.0$ & 105 \\
\hline \multirow{4}{*}{ Pear } & atrazine & n.d. & 100 & $108.2 \pm 7.2$ & 108 \\
\hline & simazine & n.d. & 100 & $101.6 \pm 6.5$ & 102 \\
\hline & cyanazine & n.d. & 100 & $97.4 \pm 8.4$ & 97 \\
\hline & propazine & n.d. & 100 & $93.0 \pm 4.4$ & 93 \\
\hline \multirow{4}{*}{ Orange } & atrazine & n.d. & 50 & $52.4 \pm 3.6$ & 105 \\
\hline & simazine & n.d. & 50 & $50.0 \pm 2.9$ & 100 \\
\hline & cyanazine & n.d. & 50 & $47.3 \pm 2.5$ & 95 \\
\hline & propazine & n.d. & 50 & $49.5 \pm 5.6$ & 99 \\
\hline \multirow{4}{*}{ Green vegetable } & atrazine & n.d. & 100 & $101.7 \pm 4.1$ & 102 \\
\hline & simazine & n.d. & 100 & $96.5 \pm 3.3$ & 97 \\
\hline & cyanazine & n.d. & 100 & $106.0 \pm 7.5$ & 106 \\
\hline & propazine & n.d. & 100 & $103.2 \pm 6.2$ & 103 \\
\hline \multirow{4}{*}{ Stewed vegetable } & atrazine & n.d. & 50 & $51.4 \pm 5.2$ & 103 \\
\hline & simazine & n.d. & 50 & $47.0 \pm 4.4$ & 94 \\
\hline & cyanazine & n.d. & 50 & $48.1 \pm 5.1$ & 96 \\
\hline & propazine & n.d. & 50 & $50.6 \pm 2.7$ & 101 \\
\hline
\end{tabular}

a Standard deviation $(\mathrm{n}=3)$. n.d.: not detected. 

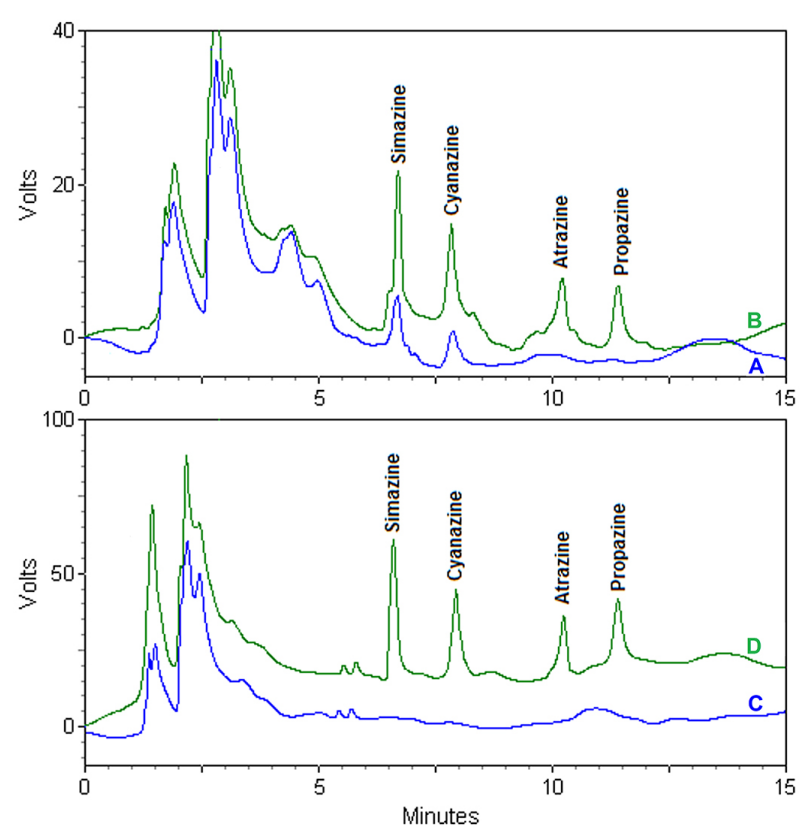

Figure 5. Chromatograms of potato sample (A), spiked potato sample at concentration level of $50.0 \mu \mathrm{g} \mathrm{kg}^{-1}$ for triazines (B), pear sample (C) and spiked pear sample at concentration level of $100.0 \mu \mathrm{g} \mathrm{kg}^{-1}$ for triazines (D) obtained by using UAE-DLLME-SFO combined with HPLC-UV. Conditions: sonication time, 15 min; type of extraction solvent in UAE stage and its volume, acetonitrile, $5 \mathrm{~mL}$, respectively; sample amount, $1.00 \mathrm{~g}$; extraction solvent in DLLME-SFO stage and its volume, 1-undecanol, $30 \mu \mathrm{L}$, respectively; volume of disperser solvent (acetonitrile), $1.00 \mathrm{~mL}$; room temperature. shows the obtained chromatograms of potato sample (A), spiked potato sample at concentration level of $50.0 \mathrm{mg} \mathrm{kg}^{-1}$ for triazines (B), pear sample (C) and spiked pear sample at concentration level of $100.0 \mathrm{mg} \mathrm{kg}^{-1}$ for triazines (D). The detailed results are depicted in Table 2.

\section{Comparison of UAE-DLLME-SFO with other extraction methods}

The efficiency of UAE combined with DLLME-SFO is comparable with conventional and other microextraction techniques to extract triazine herbicides residues from fruit, vegetables and food samples. It shows that the proposed method has distinct advantages over the others. As can be seen from Table 3, the RSDs of the proposed method are about the same with those reported for the other methods. The LODs are lower than many of the mentioned techniques, considering very low sample consumption volume except for dispersive solid-phase extraction-liquid chromatography-mass spectroscopy (DSPE-LC-MS), magnetic hollow molecularly imprinted polymer (M-H-MIP) and DLLME-SFO-GC-MS. We must take into account that many analytical laboratories cannot support such equipment because of their high price and expensive maintenance. The proposed method has acceptable liner range without

Table 3. Comparison of UAE-DLLME-SFO with other extraction methods for determination of triazines in fruit, vegetables and food samples

\begin{tabular}{|c|c|c|c|c|c|c|c|c|}
\hline Extraction method & Instrument & $\begin{array}{c}\mathrm{LOD}^{\mathrm{a}} / \\
\left(\mu \mathrm{gg}^{-1}\right)\end{array}$ & $\begin{array}{c}\mathrm{LOQ}^{\mathrm{b}} / \\
\left(\mu \mathrm{g} \mathrm{kg}^{-1}\right) \\
\end{array}$ & $\begin{array}{c}\mathrm{LR}^{\mathrm{c}} / \\
\left(\mu \mathrm{kg}^{-1}\right) \\
\end{array}$ & $\mathrm{RSD}^{\mathrm{d}} / \%$ & $\begin{array}{c}\text { Sample } \\
\text { amount / g }\end{array}$ & Sample & Reference \\
\hline ILFF-SPE $^{e}$ & HPLC-UV & $1.3-2.7$ & $4.5-9.2$ & $3-160$ & $1.44-5.21$ & 5 & vegetables & 6 \\
\hline MSPD-MIL-DLLME & UFLC-UV & $1.2-2.72$ & $3.99-9.06$ & $8-1000$ & $<7.7$ & 1 & oilseeds & 42 \\
\hline DMAE-SFO ${ }^{\mathrm{g}}$ & HPLC-UV & $1.1-1.5$ & $3.5-4.8$ & $5-1000$ & $7-8$ & 1 & cereals & 43 \\
\hline $\mathrm{PLE}^{\mathrm{h}}$ & $\begin{array}{l}\text { nonaqueous } \\
\text { CE-UV }\end{array}$ & $9-17$ & - & $25-250$ & $<10$ & 7 & fruits and cereals & 44 \\
\hline DSPE $^{\mathrm{i}}$ & LC-MS & $0.05-0.2$ & $0.1-1$ & $1-200$ & $<10$ & 10 & $\begin{array}{l}\text { fruits and } \\
\text { vegetables }\end{array}$ & 45 \\
\hline DLLME-SFO & GC-MS & $0.008-0.037$ & - & $0.01-100$ & $0.03-5.1$ & $5 \mathrm{~mL}$ & $\begin{array}{l}\text { water and } \\
\text { sugarcane }\end{array}$ & 34 \\
\hline MA-LLME-SFO & HPLC-DAD & $0.95-1.39$ & $3.15-4.63$ & $5-250$ & $<13.1$ & 2 & honey & 35 \\
\hline M-H-MIP & HPLC-UV & $0.16-0.39$ & - & $0.5-200$ & $<5.2$ & 50 & $\begin{array}{l}\text { corn, wheat and } \\
\text { soybean }\end{array}$ & 46 \\
\hline MMLLE-MIPl & HPLC-UV & $22-38$ & - & - & $0.72-1.55$ & $4-40$ & lettuce and apple & 47 \\
\hline MASE-MISPE $^{\mathrm{m}}$ & HPLC-UV & $1.3-3.3$ & - & - & 2-20 & $18 \mathrm{~mL}$ & $\begin{array}{l}\text { cow pea and } \\
\text { corn }\end{array}$ & 48 \\
\hline UAE-DLLME-SFO & HPLC-UV & $1-2$ & $3-6$ & $5-800$ & $3.6-5.4$ & 1 & $\begin{array}{l}\text { fruits and } \\
\text { vegetables }\end{array}$ & this work \\
\hline
\end{tabular}

aimit of detection; blimit of quantification; 'linear range; ${ }^{\mathrm{d}}$ relative standard deviation; ${ }^{\mathrm{a}}$ ionic liquid foam floatation solid phase extraction; ${ }^{\mathrm{f}}$ matrix solidphase dispersion combined with magnetic ionic liquid dispersive liquid-liquid microextraction; ${ }^{\mathrm{g}}$ dynamic microwave-assisted extraction combined with solidification of floating organic drop; ${ }^{h}$ pressurized liquid extraction; ${ }^{i}$ dispersive solid-phase extraction; ${ }^{j}$ microwave-assisted liquid-liquid microextraction based on solidification of floating organic droplet; ${ }^{k}$ magnetic hollow molecularly imprinted polymer; ${ }^{1}$ microporous membrane liquid-liquid extraction and molecularly imprinted polymer; ${ }^{\mathrm{m}}$ membrane assisted solvent extraction and molecularly imprinted solid phase extraction. HPLC-UV: high performance liquid chromatography with ultraviolet detection; UFLC-UV: ultra fast liquid chromatography with ultraviolet detection; CE-UV: capillary electrophoresis with UV detection; LC-MS: liquid chromatography coupled to mass spectrometry; GC-MS: gas chromatography coupled to mass spectrometry; HPLC-DAD: HPLC with diode array detection. 
using derivatization reagents and applying very sensitive determination methods like GC-MS and HPLC-MS. This extraction procedure is very simple, less time consuming and the handling of the sample is reduced.

\section{Conclusions}

The results obtained indicated that the UAE-DLLME-SFO method could extract herbicides from fruit and vegetables effectively. To the best of our knowledge, the use of UAE-DLLME-SFO for the analysis of triazine herbicides in fruit and vegetables have not yet been reported. The method shows advantages compared with other conventional methods given the short extraction time and the fact that a cleanup procedure is not used. Satisfactory linearity, recoveries, precisions, LODs and LOQs were obtained. The proposed method can be used in quality control of agricultural products, because of features like low-cost, easy-to-use and low-toxicity solvent usages. The method could be extended to other analytes and other types of fruit and vegetables samples.

\section{Acknowledgments}

The authors thank the Deputy of Research and Technology, Kermanshah University of Medical Sciences, Kermanshah, Iran for financial support.

\section{References}

1. Graymore, M.; Stagnitti, F.; Allinson, G.; Environ. Int. 2001, 26, 483.

2. Kan, C. A.; Meijer, G. A. L.; Anim. Feed Sci. Technol. 2007, 133,84 .

3. Norouzi, P.; Larijani, B.; Ganjali, M. R.; Faridbod, F.; Int. J. Electrochem. Sci. 2012, 7, 10414.

4. Garcia-Reyes, J. F.; Ferrer, C.; Thurman, E. M.; FernandezAlba, A. R.; Ferrer, I.; J. Agric. Food Chem. 2006, 54, 6493.

5. Zhang, K.; Wong, J. W.; Yang, P.; Tech, K.; Di Benedetto, A. L.; Lee, N. S.; Hayward, D. G.; Makovi, C. M.; Krynitsky, A. J.; Banerjee, K.; Jao, L.; Dasgupta, S.; Smoker, M. S.; Simonds, R.; Schreiber, A.; J. Agric. Food Chem. 2011, 59, 7636.

6. Zhang, L.; Yu, R.; Wang, Z.; Li, N.; Zhang, H.; Yu, A.; J. Chromatogr. B 2014, 953-954, 132.

7. Pirsaheb, M.; Fattahi, N.; Shamsipur, M.; Food Control 2013, 34, 378.

8. Gilbert-López, B.; García-Reyes, J. F.; Molina-Díaz, A.; Talanta 2009, 79, 109.

9. Britoa, N. M.; Navickienea, S.; Polese, L.; Jardim, E. F. G.; Abakerli, R. B.; Ribeiro, M. L.; J. Chromatogr. A 2002, 957, 201.
10. Rahnama, R.; Ghadiri, R.; J. Braz. Chem. Soc. 2015, 26, 1642.

11. Rearden, P.; Harrington, P. B.; Anal. Chim. Acta 2005, 545, 13.

12. Lang, Q.; Wai, C. M.; Talanta 2001, 53, 771.

13. Liu, J. F.; Liang, X.; Chi, Y. G.; Jiang, G. B.; Cai, Y. Q.; Zhou, Q. X.; Liu, G. G.; Anal. Chim. Acta 2003, 487, 129.

14. Xiao, Q.; Hu, B.; Yu, C.; Xia, L.; Jiang, Z.; Talanta 2006, 69, 848.

15. Hou, L.; Lee, H. K.; J. Chromatogr. A 2004, 1038, 37.

16. Li, X.; Wang, Y.; Sun, Q.; Xu, B.; Yu, Y.; Wang, X.; Talanta 2016, 148, 539.

17. Ye, C.; Zhou, Q.; Wang, X.; J. Chromatogr. A 2007, 1139, 7.

18. Rasmussen, K. E.; Pedersen-Bjergaard, S.; Trends Anal. Chem. 2004, 23, 1 .

19. Zou, N.; Yuan, C.; Liu, S.; Han, Y.; Li, Y.; Zhang, J.; Xu, X.; Li, X.; Pan, C.; J. Chromatogr. A 2006, 1457, 14.

20. Rodríguez-González, N.; González-Castro, M. J.; BeceiroGonzález, E.; Muniategui-Lorenzo, S.; Prada-Rodríguez, D.; Talanta 2014, 121, 194.

21. Makahleh, A.; Yap, H. F.; Saad, B.; Talanta 2015, 143, 394.

22. Rezaee, M.; Assadi, Y.; Hosseini, M. R. M.; Aghaee, E.; Ahmadi, F.; Berijani, S.; J. Chromatogr. A 2006, 1116, 1.

23. Melwanki, M. B.; Chen, W. S.; Bai, H. Y.; Lin, T. Y.; Fuh, M. R.; Talanta 2009, 78, 618.

24. Berijani, S.; Assadi, Y.; Anbia, M.; Hosseini, M. R. M.; Aghaee, E.; J. Chromatogr. A 2006, 1123, 1.

25. Bortoleto, M. A.; Bocato, M. Z.; Pupo, M. T.; Gaitani, C. M.; Oliveira, A. R. M.; J. Braz. Chem. Soc. 2015, 26, 1956.

26. Mohammadi, S. Z.; Afzali, D.; Fallahi, Z.; J. Environ. Anal. Chem. 2014, 94, 765.

27. Bidari, A.; Ganjali, M. R.; Norouzi, P.; Hosseini, M. R. M.; Assadi, Y.; Food Chem. 2011, 126, 1840.

28. Cunha, S. C.; Fernandes, J. O.; Oliveira, M. B. P. P.; J. Chromatogr. A 2009, 1216, 8835.

29. Ahmadi-Jouibari, T.; Fattahi, N.; Shamsipur, M.; Pirsaheb, M.; J. Pharm. Biomed. Anal. 2013, 85, 14.

30. Ataee, M.; Ahmadi-Jouibari, T.; Fattahi, N.; Int. J. Environ. Anal. Chem. 2016, 96, 271.

31. Leong, M. I.; Huang, S. D.; J. Chromatogr. A 2008, 1211, 8.

32. Shamsipur, M.; Fattahi, N.; Assadi, Y.; Sadeghi, M.; Sharafi, K.; Talanta 2014, 130, 26.

33. Rezaee, M.; Yamini, Y.; Khanchi, A.; Faraji, M.; Saleh, A.; J. Hazard. Mater. 2010, 178, 766.

34. Sanagi, M. M.; Abbas, H. H.; Ibrahim, W. A. W.; Aboul-Enien, H. Y.; Food Chem. 2012, 133, 557.

35. Hu, M.; Wu, L.; Song, Y.; Li, Z.; Ma, Q.; Zhang, H.; Wang, Z.; Anal. Methods 2015, 7, 9114.

36. Drăguş, A.; Beldean-Galea, M. S.; Coman, V.; Rev. Roum. Chim. 2014, 59, 1029.

37. Kocurova, L.; Balogh, I. S.; Sandrejova, J.; Andruch, V.; Microchem. J. 2012, 102, 11. 
38. Ahmad, W.; Al-Sibaai, A. A.; Bashammakh, A. S.; Alwael, H.; El-Shahawi, M. S.; TrAC, Trends Anal. Chem. 2015, 72, 181.

39. Leong, M. I.; Fuh, M. R.; Huang, S. D.; J. Chromatogr. A 2014, 1335, 2.

40. Da Porto, C.; Decorti, D.; Ultrason. Sonochem. 2009, 16, 795.

41. Matsumoto, S.; Varela, R. M.; Palma, M.; Molinillo, J. M. G.; Lima, I. S.; Barroso, C. G.; Macías, F. A.; Ultrason. Sonochem. 2013, 21, 1578.

42. Wang, Y.; Sun, Y.; Xu, B.; Li, X.; Wang, X.; Zhang, H.; Song, D.; Anal. Chim. Acta 2015, 888, 67.

43. Wang, H.; Li, G.; Zhang, Y.; Chen, H.; Zhao, Q.; Song, W.; Xu, Y.; Jin, H.; Ding, L.; J. Chromatogr. A 2012, 1233, 36.
44. Carabias-Martínez, R.; Rodríguez-Gonzalo, E.; MirandaCruz, E.; Domínguez-Álvarez, J.; Hernández-Méndez, J.; Electrophoresis 2007, 28, 3606.

45. Ji, F.; Zhao, L.; Yan, W.; Feng, Q.; Lin, J. M.; J. Sep. Sci. 2008, 31,961 .

46. Wang, A.; Lu, H.; Xu, S.; J. Agric. Food Chem. 2016, 64, 511.

47. Mhaka, B.; Cukrowska, E.; Sum Bui, B. T.; Ramström, O.; Haupt, K.; Tutu, H.; Chimuka, L.; J. Chromatogr. A 2009, 1216, 6796.

48. Chimuka, L.; Billing, M. P. J.; Yilmaz, E.; Jonsson, J. A.; J. Chromatogr. A 2011, 1218, 647.

Submitted: August 9, 2016

Published online: November 1, 2016 